\title{
Ownership-Based Analysis of Public Hospital Corporatisation in New Zealand
}

\section{Bronwyn Howell}

$\mathrm{N}$ early a decade after its announcement corporatisation of New Zealand's public hospitals has failed to deliver the anticipated efficiency gains. Many reasons have been offered for this failure. This paper contends that it was due primarily to the insufficient priority in the reform model to the legal and beneficial ownership rights of the New Zealand public over public hospitals.

With corporatisation, management of public hospitals was transferred from a team of medical clinical specialists accountable to a locally-elected Area Health Board (AHB) to a generic management specialist chief executive officer reporting to a board of business-experienced directors appointed by the Minister of Health. Concurrently, hospital resourcing moved from a largely capitation-based funding process of AHBs to centralised contract-based purchasing of defined quantities of hospital outputs. Prior to 1991, AHBs had both purchasing and provision responsibility for hospital-based, and many community-based, health services. Purchasing responsibility was shifted to four regional health authorities in 1993 and subsequently to a national health funding authority in 1998. These changes separation of purchasing and provision of publicly-funded services; imposition of a commercial management model; and measurement of hospital performance in financial as well as clinical terms - were heralded as the key to improved financial, operational and allocative efficiency not just of hospitals, but of the entire New Zealand health sector (Upton, 1991). The progress of the changes has been documented in a number of commentaries written since the implementation of the reforms (for exarnple, Ashton, 1999; Easton, 1997; Scott, 1996).

Although absolute efficiency gains occurring concurrently with quality improvements are difficult to measure, financial performance measures support the contention that few efficiency gains were realised. Ashton (1999:21) argues that 21 of the 23 crown-owned hospitals consistently failed to break even, deficits grew relative to those of the AHBs and other performance measures, such as numbers on public hospital surgical waiting lists, failed to show improvements. Furthermore, the Crown Company Monitoring Advisory Unit (CCMAU) noted in its report to the incoming Minister in 1996 that the reforms 'have yet to yield the original expectations. By a range of measures (for example, average length of stay, personnel costs, bed numbers) the pace of performance seems, if anything, to have weakened since the advent of the reforms'.

Bronwyn Howell is a PhD student in the School of Economics and Finance at Victoria University of Wellington, New Zealand and a research assistant at the NZ Institute for the Study of Competition and Regulation Inc. 
Popular consensus appears to support the failure of the corporatisation process as the principal reason for poor hospital performance (Vaithianathan, 1999). However, there is no consensus on the reasons for the failure of a corporate model that is used successfully in private and non-profit hospitals in many countries. Politically, the application of a profit motive in public hospitals has been questioned (Steering Group to Oversee Health and Disability Changes. 1997) Other reasons cited by economic commentators include increased transaction costs (Ashton, 1998), inability of generic managers to understand the complexities of health service delivery (Easton, 1997) and non-recognition by policy-makers of the real, but informal, authority of doctors in the corporatisation process (Vaithianathan, 1999).

While each of these explanations has some validity, none of them manages to explain adequately why the same corporate management model when applied to private, non-profit hospitals operating in the same economic environment does not produce the same adverse economic performance indicators. Private non-profit hospitals in many instances sell the same services such as elective and scheduled surgery to the same purchasing authority, have managers with generic professional management skills and are staffed in most instances by the same medical personnel as the state-owned hospitals. ' In addition, they are constrained by the non-profit motive and by similar 'political ownership' issues relating to the separation of legal and beneficial ownership, and real and formal control.

Public corporatised hospitals now differ from private non-profit hospitals principally in respect of their 'ownership' and governance profiles. Whereas nonprofit hospital boards are generally elected annually by members of the legal entity operating the hospital from a pool of members and other key stakeholders (e.g. clients and staff) and are directly accountable to and monitored by this electing body, the corporatised public hospital board is appointed at the discretion of the Minister of Health. It is accountable solely to the Minister and has negligible direct accountability to, or monitoring expectation of, any of its other key stakeholders such as clients or staff. Any accountability to the wider stakeholding is confined principally to the triennial central government election process.

This distinction indicates that explanations for the apparent failure to apply the private non-profit hospital corporate model in public hospitals may be found not in the model itself, but in changes to hospital stakeholding and 'ownership' profiles, governance structures and accountabilities as a result of the reforms. In particular, by failing to give due recognition and priority to the stakeholding interests of patients as beneficial owners and to the New Zealand public as ultimate legal owners, the reform created an environment that allowed informal ownership and governance representation to emerge.

However, without formal controls and a strictly defined set of duties and accountabilities, there was limited ability for any stakeholder to prevent the use by

1 Traditionally, New Zealand surgeons perform operations in both hospital sectors. Increasingly, nursing staff, especially contract and temporary staff, is also working simultaneously in both forms of hospital. 
de-facto agents of this informal representative agency to advance their own selfinterested agendas in addition to the public concerns. Furthermore, the nowdisenfranchised stakeholders had no ability to confine the use of this representation only to issues relating to hospital operation. Hospital management became subject to hold-up as a consequence of public reaction to reforms in other parts of the health sector, over which it had no influence or ability to control. The net effect was a significant increase in the costs of hospital management, a decrease of public confidence in the publicly funded health sector generally and the reforms in particular, and ultimately political costs for the government administration in power when the reforms were enacted. Thus, Vaithianathan's observations of changes in the balance of the real and formal authority of doctors, and to some extent Ashton's observations of increases in transaction costs, can be explained as consequences of changes in the representation of patient and public interests in the health reform process.

\section{Ownership of Non-Profit Organisations}

Theories on the ownership of organisations provide a basis for understanding the dynamics of the change in New Zealand's public hospitals as a result of corporatisation. Hansmann (1996) theorises that, free of constraints, ownership rights in an organisation will generally devolve to the group of stakeholders that act to maximise the total net benefits of the firm and its stakeholders. These net benefits are dependent upon both the costs of market contracting (market power, risks, information asymmetry, bargaining costs, patron preference costs) and the costs of ownership (governance, monitoring, costs of poor decision-making, costs of risk-bearing).

As noted by Hansmann, in certain circumstances, the overall most efficient outcomes for all stakeholders can be obtained where there is no effective formal control by any one set of owners - that is, the classic non-profit firm. These circumstances generally arise where the costs of both market contracting and ownership are exceptionally high for a specific class of stakeholders. Such stakeholders are typically either customers in a poor position to determine the quality or quantity of services they receive from a firm because of severe information asymmetry, or customers in a market characterised by absence of competition. Assigning ownership to anyone but these stakeholders creates the opportunity for severe exploitation and consequent inefficiencies. However, due to their diverse spread and the relatively small value of the benefits transferred, the costs of including them in the control processes of ownership are too large. To overcome the high costs of ownership, the solution is to create virtual owners where managers of the firm hold it in trust for their beneficiary customers. 'In essence, the non-profit firm abandons any benefits of full ownership in favour of stricter fiduciary constraints on managers.' (Hansmann, 1996:228).

The efficiency of the non-profit form relies upon both the effectiveness of the fiduciary duties to protect the interests of the beneficiary-owners and the ability of stakeholders to monitor and enforce the performance of those duties. So, although 
the non-profit firm may not have 'owners' in the sense of residual claimants (Milgrom and Roberts, 1992), it must still operate in a manner that enables a balance between the interests of the beneficiary-owner and the power of a strong stakeholder who might otherwise act opportunistically. In effect, the fiduciaries must act principally as agents of the beneficiary-owner principals, although there may only be an implicit contract between them and limited mechanisms via which the beneficiary-owners can directly call their agents to account. Accountability rests entirely within the processes by which the fiduciaries are appointed. Therefore, unless the appointment, operating and accountability processes can reflect, monitor and enforce the beneficiary-owner's interests, the very conditions that the non-profit form was designed to avoid - exploitation by a strong stakeholder - will occur and the total net benefits of the firm and its stakeholders will not be maximised (Howell, 2000a).

Thus, the first key to efficient operation of a non-profit organisation lies in identifying how beneficiary-owner interests within the firm will be translated into fiduciary duties. These duties must reflect, as with for-profit organisations, ultimate ownership of both the rights to ownership of residual returns and the rights to ownership of residual control (Fama and Jensen, 1983a). Williamson (1983) identifies that beneficiaries of non-profit organisations possess some of the rights of residual owners, as they constitute the only group of stakeholders to whom any distribution of residual profits can be legitimately made. Fama and Jensen (1983b) demonstrate that, even though they have no residual profit ownership rights, decision-makers in non-profit organisations own responsibility for residual control. However, while residual ownership and control in a for-profit organisation resides solely in the shareholder-owners, in non-profit organisations it is likely that these ownership rights will ultimately reside in different stakeholder groups (Howell, 1999).

The fiduciary duties for a non-profit organisation, therefore, should take cognisance of the distinctions between legal and beneficial ownership. They also need to recognise where stakeholder interests are distinctly separate and where they overlap. For instance, in a mutual organisation beneficial owners are also legal owners as only members can receive benefits. However, in a philanthropic trust there is often complete separation as trustees are generally prohibited from being beneficiaries. Furthermore, the membership (legal owners) of a serviceproviding non-profit organisation may include some that are concurrently beneficiaries and some that are not. Howell (1999 and 2000) provides additional clarification. In practice, the distinction is often achieved via proportional membership of the governing body by elected agents representing each of these interests. Such balance is important to avoid the supremacy of one set of interests over another (Wood, 1996) and the subsequent inefficient outcomes that result when only one of multiple principal-agent tasks is subject to incentives and performance measurement (Holstrom and Milgrom, 1991).

Monitoring and measuring mechanisms to enable principals to assess the performance of the fiduciary duties of their agents and to hold them accountable in the event of inadequate performance must also be included. Again, in practice this 
is often achieved via the annual reporting and election process tailored to reflect the ownership requirements of the (potentially) separate beneficial and legal owners.

The second key to efficient operation relies upon understanding the interactions of the organisation and its stakeholders in the market in which they operate. As Hansmann (1996) indicates, the ownership form of any organisation is adopted because it maximises net benefits to the firm and its stakeholders. However, as the market is a dynamic system, the manner in which stakeholders interact outside the firm may affect the balance of stakeholder power within the firm (Senge and Sterman, 1992). Where shares of the firm are readily tradeable, Hansmann demonstrates that changes in the balance of stakeholder power, either internally or externally, are reflected in a change of the stakeholding profile of the shareholder owners. But, in the absence of a market for ownership and control of a non-profit organisation, the only way by which such changes in stakeholder relationships can be reflected is by a change in the fiduciary duties of the board and its management. Any ability for the duties to change spontaneously in response to external changes is confined within the ability of the fiduciaries to both identify changes and adjust their duties accordingly. Unless these adjustments are based on reliably interpreted signals from the external environment, changes in the way stakeholders interact in the wider system may lower net benefits to the organisation and its stakeholders below the level that might have been achieved under a more flexible system.

\section{Hospitals as Non-Profit Organisations}

The evolution of hospital ownership in New Zealand recognises the strong informational asymmetries present in the health care market. Medical staff, and doctors in particular, hold a strong informational advantage over both patients and hospital owners regarding the form, quality and quantity of care or treatment required (Vaithianathan, 1999). By Hansmann's arguments, in order to overcome this advantage for the overall benefit of all stakeholders, there is a strong incentive for hospitals to be owned by patients. The solution to the practical difficulties and significant costs of each individual patient having a separate ownership share is to adopt the non-profit form.

In New Zealand two distinct non-profit hospital forms have evolved. State ownership on behalf of patients and the public, utilising the processes of political and government accountability to represent patient and public owner interests (for example, the Public Finance Act and the triennial national election process) is, by far, the most prominent ( 95 per cent of hospital services). The others are mostly under the control of private non-profit enterprises and are typically managed by trustees within a strictly defined set of fiduciary duties designed to minimise individual exploitation and preserve the rights of patients. Non-profit trustees are accountable via publicly published statements and a public election process. Furthermore, where the organisation has a membership, these members also have implicit fiduciary duties to the public. Thus, the membership plays an important 
role in both disciplining the board of trustees and providing an additional avenue of representation for non-member beneficiaries in the decision-making process (Mason, 1984; Howell, 1999). However, each of these non-profit ownership forms reflects the separation of the right to the benefits distributed via hospital treatment services (beneficial ownership) from the rights of the public to ensure that their interests as technical owners (or in the case of non-profit members, as fiduciaries for the public interest) of the hospital's assets are preserved in the operation of the business (legal ownership).

\section{Beneficial and Legal Ownership and the Hospital Reforms}

Prior to the reforms of the last decade, specific communities elected members of a local AHB to manage the delivery of hospital and some related health services. The local election process clearly identified subsets of electors as each hospital's ultimate 'legal owners' in a similar manner to members of a mutual organisation. As evidenced by significant local protest when hospital closures were sought, this process ensured strong legal ownership representation at board level and reinforced a strong cultural sense of public ownership of the physical assets of the hospital. In addition, as the patient-beneficiaries of the hospital's services were also concurrently 'legal owners', this process allowed for an additional, although weaker, representation of beneficial ownership interests at board level. ${ }^{2}$

Representation of the interests of patients as beneficial owners, however, was conducted at both the governance and management level predominantly by the clinical executive management team. While accountable to the public owners as agents of both legal and beneficial owners, the clinical management team was simultaneously accountable to their patient principals for the elements of care relating to patient benefits. By placing both agency relationships directly in the same management team, the public hospital management process achieved some balancing of principal interests. Furthermore, this process replicated the dual agency present in the trustee managers of private non-profit hospitals who have ultimate responsibility for both the clinical care of patients and for the effective operation and maintenance of the hospital assets.

The pre-1991 AHB model was far from a perfect governance structure for the operation of public hospitals. Political election and appointment processes often resulted in large and cumbersome boards with imbalanced skill mixes (Upton, 1991). Confused accountabilities of AHBs between central government and local electorates opened opportunities for self-interested political agendas to be pursued at the Board level (Gibbs, Fraser and Scott, 1988). Government allocation of funds created a soft budget constraint that combined with absence of competition to erode incentives for AHBs to perform in a fiscally responsible manner. It also reinforced the ability of local politicians to appeal to, and rely upon, central government intervention, thus further confusing accountabilities and

2 Weaker because the ratio of beneficiaries to voters was small, with only a fraction of the voting population (or their dependents) accessing hospital services during the three year period. 
responsibilities (Howell, 2000b). In addition, the dual responsibilities to allocate funds and provide services led to operational decisions that favoured provision of AHB services over other provider options, even though in many instances public provision was constrained by severe operational inefficiencies (Arthur Anderson report, cited in Gibbs, Fraser and Scott, 1988).

Despite the shortcomings, the 'mutual agency relationship' of the management team ensured that the beneficial and legal public ownership issues could be addressed simultaneously at the same table. These managers were subject to the dual disciplines of their professional accountability to patients and their employee accountabilities to political principals, requiring each decision to be made with both stakeholdings in mind. That is, they executed the two distinct fiduciary duties to the public owner simultaneously via two separate accountability mechanisms.

The 'corporatisation' process led to two significant changes in the alignment of beneficial and legal ownership agencies. First, by appointing professional executive managers, direct representation of, and accountability to, patient beneficiaries in executive decision-making was lost. The principal accountability of the new managers was solely to the legal public ownership represented by the minister and the ministerially appointed board. All performance measures were aligned to discharging this ownership duty (financial returns on assets) with patient-beneficiary advocacy relegated to second-tier clinical staff. As predictable from Holstrom and Milgrom (1991), and evidenced by Vaithianathan (1999) and Ashton (1999), measurable activities and incentives relating to financial performance (for example, CHE Chief Executive's incentive-based remuneration) seem to have been given higher priority than hard to measure and poorly rewarded activities such as improvement in population-based health status indicators.

Second, the capacity for either patient-beneficiaries or individual public owners to voice their ownership rights in their local hospital or call their fiduciaries to account was eliminated when the locally-elected AHBs were replaced by ministerially-appointed boards, whose fiduciary responsibilities were limited to legal ownership. Direct accountability to beneficiary ownership was thus restricted to the national parliamentary political process where it was effectively diluted amongst accountabilities for all other political ownerships (for example, schools, prisons, and other government-owned businesses). Public ownership accountability was further diluted by the 'purchaser-provider split', which separated the accountabilities for purchasing patient benefits from providing services. The purchasing bodies (initially four Regional Health Authorities later merged into a single Health Funding Authority) were also not directly accountable to their beneficiary-owners. , All accountabilities for crownowned hospital boards were channelled through CCMAU. Although CCMAU had delegated responsibility from the Minister to monitor financial performance (that is, legal ownership), it had no direct access to beneficiaries outside of the political process that would allow it to monitor hospitals' performance against beneficial ownership objectives. Each successive level of division further 
restricted the ability to balance both of the public ownership rights at the same table and further disenfranchised the beneficial owner.

The result had three significant impacts. The first was the local optimisation of each ownership process without consideration of their impact on each other. The inability or lack of incentive to resolve conflicts in the interests of the combined legal and beneficial owner, the results resembled the sub-optimal noncooperative outcomes of a two-player game (Milgrom and Roberts, 1992). This is illustrated in Vaithianathan's examples of holdup by doctors in the contract negotiation process, where optimisation of ownership interests represented by management clashed with optimisation of beneficial ownership interests represented by doctors with the consequence that the combined beneficial and legal owner lost out on both counts with no redress possible (Ashton 1998).

The second impact was a significant increase in the cost of hospital ownership. Coordination of all the diverse interests, previously combined in a single management structure, now had to be procured at financial cost, both in terms of explicit purchase of coordination and the hidden costs of inefficient optimisation of the interests of only one of the stakeholder ownership components. Information critical to decision-making and performance monitoring, which had been jointly available and freely shared for the purposes of carrying out fiduciary duties, now also had to be explicitly purchased by each of the separated agents (Ashton, 1999). This added to physical costs and compromised the quality of information available for decision making as it often had to pass through several links of the principal-agent chain with potential dilution through filtering at each step (Brynjolfsson, 1994). Thus, the divided accountability structures imposed additional costs of accountability on hospitals, resulting in a consequent reduction in the value of the hospital organisation (Jensen and Meckling, 1976), which the nonprofit reliance on fiduciary duties was designed to avoid (Hansmann, 1996).

The third impact was the move by doctors to fill the void of patientbeneficiary representation at hospital management level (Vaithianathan, 1999). While clinicians had been removed from key decision-making processes in executive management, as patient-advocates they were left closest to the hospital executive decision-making process of any of the patient-agents as a result of the restructuring. As restoration of the natural equilibrium required the patient beneficiary representation void to be filled, the patient-agents best equipped to fulfil this role - doctors - sought to gain some control of the executive process. However, without formal control, the only way that the equilibrium could be restored was by strengthening their effective control. Legitimate beneficial agency representation on behalf of their patients was possible, but this limited stakeholder power base was too small to counter the strength of the legitimate ownership control exercised by management. Thus, by seeking and gaining wider public support for their representative activities, they assumed an informal proxy representation status for the otherwise disenfranchised wider public ownership.

The result was the increased political advocacy roles of umbrella groups such as the Medical Council and the Specialist Association as evidenced by Vaithianathan (1999). The effective power of these groups was increased by 
public support. However, as the representation was informal, it lacked the discipline of a specific accountability process or any explicit fiduciary duties with respect to the public's legal ownership stake. Consequently, there was little ability for the public to either monitor or constrain the umbrella groups' use of their newly reinforced power to advance their own personal agendas as well as those of their public quasi-principals. Furthermore, this newfound agency added unconstrained power to the stakeholder whose informational advantage over patients was one of the principal economic justifications for hospitals adopting the non-profit form in the first place. While Vaithianathan's findings indicate that the real but unrecognised power of doctors was overlooked in the application of the corporate model, this organisational ownership analysis shows that the governance structure of the corporate model created an opportunity for doctors to actually increase their effective power unchecked by any formal accountability process. Opportunistic exploitation of this unconstrained power by an already advantaged stakeholder was inevitable with consequential efficiency losses rivalling those incurred in the former imperfect, but more equitable, representative process.

\section{Hospital Corporatisation in the Health Market Context}

The efficiency losses that accompanied corporatisation beg the question of why similar efficiency losses are not experienced by the New Zealand private nonprofit hospital sector, which utilises a similar corporate structure. The key to this lies in a full stakeholder and market dynamics analysis.

\section{Organisational viability}

Despite the presence of the nondistribution constraint, private non-profit hospitals exist as separate and distinct trading organisations. Survival depends upon the ability of the organisation to meet both its financial and its social objectives. Failure to meet, in particular, its financial objectives, will result in the demise of the organisation. Notwithstanding the well-meaning intentions of donors who may shore up budget deficits with increased contributions, the soft budget constraint which characterises public hospital operation does not exist to anywhere near the same extent in private non-profit hospitals. Private non-profit hospitals can, and do, cease to exist if they consistently fail to meet financial objectives (for example, the closure of Karitane Hospitals by the Plunket Society in the 1970s) with consequent loss of reputation for the organisation, its fiduciaries if the demise is attributable to their governance performance, and the members as ultimate legal owners of the non-profit entity. This threat of financial failure, with its concomitant threat of failure to deliver upon the organisation's social objectives, acts as a strong incentive aligning the diverse representative interests of all decision-making stakeholders in the private non-profit hospital and provides additional incentives for the pursuit of internal operating efficiencies.

In particular, private non-profit hospitals have two additional stakeholder classes absent from the public model - paying customers and donors - who exert an additional performance discipline upon the board and management. Even 
though they make a part-payment, non-profit hospital customers are nonetheless beneficiaries of reduced fees as a result of cross-subsidisation from other fundraising. However, if the managers make a decision which breaches their beneficiary rights, such as the excessive personal opportunism which increases the part payment required or reduces the quality of service offered, the beneficiary group can discipline that management by voluntarily withdrawing their custom and patronising another private non-profit hospital. Medical insurance companies as customer-agents can also exert a purchasing discipline on private non-profit hospital managers and trustees, notwithstanding any beneficiary status. Similarly, if donors perceive that their donations are not being applied in the manner intended, they will also withdraw their support. In either case, the private nonprofit hospital increases its risk of failure. These disciplines bind the behaviour of both managers and trustees in the execution of their legal owner duties to further the interests of beneficiaries within the constraints imposed by ongoing financial viability. Thus the market for customers and donors imposes disciplines upon the boards of private non-profit hospitals.

In addition, the boards of private non-profit hospitals have the autonomy to make all policy and operational decisions regarding their activities, including the range and quality of services provided. They are generally not constrained in their ability to amend both services provided and fiduciary duties to their legal and beneficial owners in response to changes in the market, notwithstanding any constitutional requirements to seek member approval to do so. In this respect, private non-profit boards retain much of the flexibility of their for-profit counterparts (Howell, 1999), a strength aspired towards in the State-Owned Enterprise model (Evans, 1993).

\section{Extra-organisational influences}

The governance structure of the public 'corporatisation' model overlooked the interests of beneficiary owners and failed to account for the changes in beneficiary representation associated with purchasing. It also failed to account for the discipline that beneficial owners, donors and purchasers impose on non-profit hospital management. Prior to the reforms, capitation funding provided hospitals with some discretion over the range of services they provided. Beneficial ownership representation in decisions regarding the range, quantity and quality of service delivery was achieved to some extent at the board level. A board (and by extension its management) that failed to provide its patient-customers with the expected range, quantity and quality of services had to bear the risks of its own political failure directly from a dissatisfied electorate. This approximated the way the board of a private non-profit hospital risks foreclosure if it fails its part-paying patients and donors.

The purchaser-provider split meant that the hospitals' customers were to all practical effect the purchasing authority rather than the patient. Indeed, the jargon of the reforms talks freely of hospitals 'earning revenue in an internal market supplying services to the newly-created Regional Health Authorites' 
(Vaithianathan, 1999), despite services actually being delivered to patientbeneficiaries. While actual provision occurred in hospitals, where the patientbeneficiary monitored the range, access to, and quantity and quality of services provided, the hospital board and management were responsible only for quality of services provided. Responsibility for all other aspects lay with the purchasing authority that, as a non-profit state-owned entity, was also governed by a set of fiduciary duties. Yet, neither the hospital service provision systems nor the purchasing authority mechanisms facilitated direct monitoring or enforcement of performance of their fiduciary duties by the pivotal stakeholder in hospital service provision - the patient-beneficiary. This change in stakeholder and agency relationships in the wider health market left a gap in hospital management disciplining. Without a direct patient signalling mechanism at the hospital level, the public corporate model lacked one of the key monitoring elements of both the private non-profit hospital and the standard state-owned enterprise models (Evans, 1993). Further compounding this, while the purchasing body could discipline hospital management for poor performance by applying patronage constraints, beneficiaries could not discipline the purchasing agency management in any direct manner for hospital purchasing activities that affected their beneficial status. This opened yet another market for patient representation to the professional umbrella groups. As they were already engaged in advocacy with hospital management, there were economies of scope available to these groups to extend that advocacy role to matters of beneficiary disenfranchisement at the purchasing level as well. Public hospital management thus became hostage to holdup, not only as a result of its own internal activities, but also as a result of the activities of the purchasing body. Vaithianathan's example of staff at one hospital refusing to carry out operations purchased on behalf of a second hospital is evidence of this. Again, while the patient-beneficiary may have gained some representation, the ownerbeneficiary paid the cost of both the advocacy and the efficiency losses due to any concurrent opportunistic advancement of agents' personal agendas.

Furthermore, individual hospital boards were constrained by the statutory rigidities of the purchaser-provider split and tightly defined fiduciary duties linked specifically to discharging their duties to the legal owner interests. Unlike most private non-profit hospitals, public hospital boards lacked a membership's constitutional ability to amend the fiduciary duties of board members in response to changes in the market. Instead, public hospital boards were inflexible in their ability to change until political policy-making and legislative processes could amend these duties. This inflexibility meant public hospital boards had no option but to persist with financially driven objectives even when these objectives and changes in other parts of the health sector were resulting in escalations in the costs of hospital ownership. Only political intervention, in the form of the removal of the requirement to return a dividend to the government in excess of the cost of capital by the 1996 National-New Zealand First Coalition, was able to loosen the dominance of legal ownership interests in the governance of hospitals. However, with the preservation of the purchaser-provider split, it is debatable whether this has had any real effect in redressing the lack of beneficiary owner representation. 


\section{Implications for Future Policy-Making}

The failure of the public hospital corporatisation process, however, should not be interpreted as either a structural failure of the model or as a reason to replicate the ways of the past. The private non-profit application of this structure shows that with balanced stakeholding representation, recognition of all ownership interests both legal and beneficial and effective fiduciary accountability, the corporate model has a role in achieving greater operational efficiencies in a non-profit, and hence state-owned, hospital environment. The AHB structure, while offering some level of direct public input in hospital management processes, provided far from ideal representation due to biases and opportunism related to its own political accountabilities, agendas and purchasing power. Hence, it appears to offer little in the way of new approaches to the representation dilemma, especially given the wide-reaching nature of the reforms elsewhere in the health sector.

If policy-makers wish to apply the private non-profit governance structure to pursue increased efficiency in public hospitals operations, then attention should be given to the key areas where the New Zealand experiment has been shown to have failed. Boards must be made more directly accountable to both their beneficiary and legal owner constituencies. As long as public ownership of hospitals is perceived to be desirable, there appears to be a need for at least some locally elected membership of boards accountable directly for legal ownership issues. But these boards must have the same freedom as their private non-profit and stateowned enterprise counterparts to both manage their own strategic direction and be held accountable for the outcomes of the decisions they, and only they, make.

However, this must be developed in tandem with mechanisms that address beneficial ownership interests just as directly. The purchaser-provider split did not provide the ability to discipline hospital boards and management in matters of beneficial interest in the manner as is observed in the behaviour of donors and purchasers in the private non-profit model. The outcome should not be interpreted as failure of the governance model. Rather, it should be seen as a failure by policymakers to effectively duplicate the disciplines inherent in the private nonprofit model in the purchaser-provider split. This indicates that potential to gain additional efficiencies still exists if these disciplines can be duplicated, but the solution lies outside the hospitals themselves. Giving beneficiaries the power to express their preferences by exiting and taking their government funding entitlement elsewhere, be that to a private non-profit hospital or another public hospital, may be a possibility. The key here is the mobility of funding with beneficiaries. Flood (1999) notes the perverse incentives of public purchasing programs where patients exit from the state-funded system but are unable to take their funding with them. In such a situation there would be an incentive for public funders to deliberately encourage this behaviour as the per capita funding for those remaining increases, thus inhibiting a complete and reliable assessment of the funder's performance. Such a system may also serve to separate clearly in the minds of the public the entitlement to funding from the provision of services. 
In addition, if the governance structure were to rely upon fiduciary accountability rather than accountability direct to the beneficial or legal owners, then the duties of the board members carrying out those responsibilities must address both ownership components in a balanced manner. Furthermore, performance by the fiduciaries of those duties must be measured, monitored and enforced, even to the extent of incurring personal reputation liability or organisational failure, if the incentives of the private non-profit structure and their efficiency-related outcomes are to be duplicated.

Thus, the salutary lesson for policy-makers from the New Zealand hospitals' experiment with 'corporatisation' of a state operation is that changes that do not take account of the full stakeholding profiles of the organisation are likely to fail. As state-owned organisations are non-profit organisations, there must be a careful analysis of the public's separate and distinct rights as beneficial and legal owners, and of the public's rights and responsibilities as customers and final consumers, even when the benefit is being purchased on their behalf. For in the final analysis, the primary stakeholders in any organisation are its owners and its customers directors, managers and employees are merely brokers who facilitate an exchange of value which, if well-designed, will enhance the position of both of these primary stakeholders. Hence, any change must look at the needs of owners and customers first. It was failure to give due priority to the needs of the beneficial owner that precipitated the failure of the hospital reforms. The behaviour of other stakeholders subsequent to the reforms was a direct consequence of this, but not, as Vaithianathan and others have argued, the cause of the failure.

\section{References}

Ashton, T. (1998), Quasi Markets and Contracting for Health Services, University of Auckland.

Ashton, T. (1999), 'The Health Reforms: To Market and Back', pp 134-153 in Boston, J., P. Dalziel and S. St John (eds), Redesigning the Welfare State in New Zealand: Problems, Policies and Prospects, Oxford University Press, Auckland.

Brynjolfsson, E. (1994), 'Information Assets, Technology and Organisation, Management Science 40(12):1645-1662.

Crown Company Monitoring Advisory Unit (1996), 'Briefing to the Incoming Minister', Wellington.

Easton, B. (1997), The Commercialisation of New Zealand, Auckland University Press, Auckland.

Evans, L. (1993), 'Microeconomic Reform of the New Zealand Public Sector', The Australian Economic Review 4:11-16.

Fama, E. and M. Jensen (1983a) 'Separation of Ownership and Control', Journal of Law and Economics 6:301-26.

Fama, E. and M. Jensen (1983b), 'Agency Problems and Residual Control', Journal of Law and Economics 6:327-349.

Flood, C. (1999), International Health Care Reform: A Legal, Economic and Political Analysis, Routledge, Andover. 
Gibbs, A., D. Fraser and J. Scott (1988), Unshackling the Hosptials, Hospital and Related Services Taskforce, Wellington.

Hansmann, H. (1996), The Ownership of Enterprise, Harvard University Press, Cambridge, Mass.

Holstrom, B. and P. Milgrom (1991), 'Multitask Principal-Agent Analyses: Incentive Contracts, Asset Ownership and Job Design', Journal of Law and Economic Organisation 7:24-52.

Howell, B. (1999), 'Contracting and Nonprofit Organisations', Victoria University of Wellington, Graduate School of Business and Government (Management Project Report Series 21).

Howell, B. (2000a), 'Towards a New Taxonomy of Nonprofit Organisations', New Zealand Institute for the Study of Competition and Regulation Inc. Working Paper, www.iscr.org.nz/research

Howell, B. (2000b), 'New Zealand's Area Health Boards 1980-1991', New Zealand Institute for the Study of Competition and Regulation Inc. Working Paper, www.iscr.org.nz/research

Jensen, M. and W. Meckling (1976), 'Theory of the Firm: Managerial Behaviour, Agency Costs and Ownership Structure' Journal of Financial Economics 3:305-60.

Mason, D. (1984), Voluntary Nonprofit Enterprise Management, Plenum, New York.

Milgrom, P. and J. Roberts (1992), Economics, Organisation and Management, Prentice Hall, New Jersey.

Scott, G. (1996), Government Reform in New Zealand, International Monetary Fund, Washington DC (Paper No. 140).

Senge, P. and J. Sterman (1992), 'Systems Thinking and Organisational Learning: Acting Locally and Thinking Globally in the Organisation of the Future', European Journal of Operational Research 59:137-150.

Steering Group to Oversee Health and Disability Changes (1997), Implementing the Coalition Agreement on Health, Report of the Steering Group to Oversee Health and Disability Changes to the Minister of Health and the Associate Minister of Health, Ministry of Health, Wellington.

Upton, S. (1991), 'Your Health and the Public Health: A Statement of Government Health Policy', Office of the Minister of Health, Wellington.

Vaithianathan, R. (1999), 'The Failure of Corporatisation: Public Hospitals in New Zealand', Agenda 6(4):325-338.

Williamson, O. (1983), 'Organisation Form, Residual Claimants and Corporate Control', Journal of Law and Economics 26:351-366.

Wood, M. (1996), 'Governance and Leadership in Theory and Practice', pp. 1-17 in Wood, M. (ed.), Nonprofit Boards and Leadership, Jossey-Bass, San Francisco.

The author wishes to thank Judy Bethwaite, Charles Cangialose, Lewis Evans, Neil Quigley and the anonymous referees for comments on earlier drafts of this article. The author also acknowledges the editorial assistance of Agenda. 